\section{Primäre Insomnien}

Helga Peter

Marburg, Deutschland

\section{Synonyme}

Primäre Schlaflosigkeit

\section{Englischer Begriff}

primary insomnias

\section{Definition}

Der Begriff geht auf das DSM-IV (1994) zurück, wo er erstmals als diagnostische Entität auftaucht. Die Diagnose konnte gestellt werden, wenn es sich um ein eigenständiges Krankheitsbild handelte, d. h. die Insomniesymptomatik nicht auf eine organische oder psychische Ursache oder eine Substanzwirkung zurückzuführen war. Im DSM-5 (2013) wurde das Konzept der primären und sekundären Insomnien zugunsten der Diagnose $>$ „Insomnien“ (insomnia disorders) verlassen. In den schlafmedizinischen Klassifikationssystemen fand der Begriff zu keiner Zeit Anwendung.

Siehe auch $\triangleright$,Diagnostische Klassifikationssysteme“. 